January 2004

\title{
Organizational Barriers to Inclusion: Perspectives from the Recreation Professional
}

Dan K. Hibbler Ph.D.

DePaul University, dhibbler@depaul.edu

Follow this and additional works at: https://via.library.depaul.edu/snl-faculty-pubs

Part of the Leisure Studies Commons, Race and Ethnicity Commons, and the Recreation, Parks and Tourism Administration Commons

\section{Recommended Citation}

Hibbler, Dan K. Ph.D.. (2004) Organizational Barriers to Inclusion: Perspectives from the Recreation Professional. Leisure Sciences.

https://via.library.depaul.edu/snl-faculty-pubs/40

This Article is brought to you for free and open access by the School of Continuing and Professional Studies at Digital Commons@DePaul. It has been accepted for inclusion in School of Continuing and Professional Studies Faculty Publications by an authorized administrator of Digital Commons@DePaul. For more information, please contact digitalservices@depaul.edu. 


\title{
Organizational Barriers to Inclusion: Perspectives from the Recreation Professional
}

\author{
MARIA T. ALLISON \\ Department of Recreation Management and Tourism \\ Arizona State University \\ Tempe, Arizona, USA
}

DAN K. HIBBLER

DePaul University

Chicago, Illinois, USA

\begin{abstract}
Recreation professionals continually strive to serve a host of diverse program constituents, while leisure researchers attempt to uncover barriers to leisure participation. Much of the barriers or constraints research has come from the perspective of program participants. This study identified, from the perspectives and experiences of 18 recreation professionals, the issues and barriers that they perceive inhibit recreation program access and availability to diverse constituents, particularly ethnic minority populations. Co-cultural theory, which integrates the concepts of muted group theory and standpoint theory, was utilized as the study's theoretical framework. In-depth interviews were utilized. Five primary barriers were identified that related to the changing faces of the community, the changing faces of management and staff, deferred program responsibility, language barriers, and negative attitudes and stereotypes held by some management and staff. This article demonstrates how these barriers impact leisure participation for disenfranchised groups. The findings suggest that recreation agencies, often unwittingly or unknowingly, foster organizational barriers that inhibit the perceived program accessibility or attractiveness to ethnic minorities. Implications for research and professional practice are explored.
\end{abstract}

Keywords ethnicity, co-cultural theory, muted group theory, standpoint theory, program access, diversity, organizational barriers

Public recreation and leisure programs are environments where social equity and democratic principles are promoted (Allison, 2000a; Bialeschki \& Hendeson, 2000; Scott, 2000). Tax supported recreation and parks programs strive to serve a wide range of constituents regardless of gender, ethnicity, social class, sexual orientation, age, and ability. Most leisure literature presumes some implicit sense of goodness and equity in the profession's organizational missions and program goals. Although such a position may indeed be tenable, its assumed existence can foster organizational complacency with regard to the treatment of marginalized and disenfranchised populations. There are institutional and structural barriers

Received 24 October 2002; accepted 10 October 2003.

The College of Public Programs Dean's Incentive Grant provided funding for the data collection portion of this project. The authors gratefully acknowledge the insightful comments provided by the reviewers of this manuscript.

Address correspondence to Dr. Maria T. Allison, Department of Recreation Management and Tourism, Arizona State University, P.O. Box 874905, Tempe, AZ 85287-4703. E-mail: maria.allison@asu.edu 
agencies themselves create, or unknowingly promulgate, that inhibit program access and opportunity to diverse constituents, including people of color. Coupled with the institutional barriers there may be a host of interpersonal barriers manifested in the negative attitudes and stereotypes held by some management and staff that may help foster or reinforce the marginalization of these constituents. The interplay of these levels of institutional and interpersonal barriers creates a complex interactive environment that marginalized individuals must negotiate as they communicate and interact in recreation programs.

Recent research in the area of co-cultural communication (Orbe, 1998) provides valuable conceptual approaches to better understand the organizational complexity of dominant and non-dominant group relations in recreation environments. Specifically building on the work of muted group theory (Kramarae, 1981) and standpoint theory (Smith, 1987), Orbe suggests that many co-cultural groups (e.g., women, people of color, gays, bisexuals) living simultaneously in society must negotiate, through communication and interaction, their place in relation to one another. However, according to this theory, power rests in the hands of members of the dominant hierarchy (i.e., European American white, male, heterosexual) who, in the public sphere, "set" the parameters of interaction in our major societal institutions (Orbe). Accordingly, the experiences of those in the non-dominant groups are muted or "made invisible by the pervasiveness of the dominant culture (Samovar \& Porter, 1994)." Moreover, standpoint theory, which emerged from feminist work of Harding $(1987,1991)$, Harstock (1983), and Smith (1987) and has subsequently been applied to the experiences of other disenfranchised populations (Smith, 1987), requires that in order to understand co-cultural relations one must explore the life experiences of those situated in subordinate positions. Those whose daily life experiences are on the fringes of the dominant power structures are best positioned to assess dominant group structures from various vantage points.

Co-cultural theory, then, provides a framework to assess, from the perspective of historically marginalized individuals, their view of the intersection between dominant and non-dominant relations within existing social structures. For our purposes, it is important to acknowledge that the recreation agency environment becomes a specific context in which these communicative and interactive processes take place. The recreation program becomes the very place where dominant and non-dominant relations are played out. The behaviors of management and staff, and the policies and practices of the organization, set the tone for the success (or lack thereof) of the subsequent interactions between marginalized individuals and the agency itself.

In recent years, there has been an increased recognition that there is a need for research that analyze the ways that recreation-related agencies and programs respond to ethnically diverse clientele (Allison, 1999, 2000a, b; Floyd, 1998; Philipp, 1995, 2000; Scott, 2000). The lack of such research to date may be due, in part, to the assumption that the recreation profession is founded on egalitarian principles that translate into equitable personnel, policies, and procedures and that such research is not needed. Moreover, since individuals who pursue human service related careers are often motivated by a desire to serve historically disenfranchised or marginalized populations (e.g., elderly, the poor, ethnic minorities, and persons with disabilities) it may be assumed that issues of discrimination and inequitable treatment are not as salient in such professions. As James (1996) notes, many human service professionals are frustrated by the suggestion that their practices and policies reinforce inequities that exist in the larger society. However, to assume that the will to serve others is sufficient to ensure that clientele are treated equitably oversimplifies the very complex nature of organizational life. It assumes that all management and staff have the knowledge, sensitivity, and skills to work with diverse populations, and it also ignores the embedded nature of bias, stereotypes, and institutional discrimination that may exist in our programs. 


\section{Purpose}

This research project explores, from the perspectives and experiences of eighteen recreation professionals, specifically women and people of color, the types of issues and barriers that they perceive exist within parks and recreation agencies that may inhibit program access for people of color. Respondents were asked, when possible, to provide specific examples of the types of issues and barriers they had observed that they felt influenced program attractiveness or accessibility. The following general questions formed the foundation of this investigation.

1. Who is your customer and what is the demographic nature of your service area? How do you serve the needs of the diverse populations you serve? Have the demographics changed over the last ten years and, if so, how has that changed your service delivery?

2. From your perspective, what are the types of organizational practices and policies, if any, that you have observed that may make our programs more or less attractive or accessible for people from diverse ethnic populations (e.g., staff composition, culturally relevant programming, community outreach, diversity training)?

3. What are the types of management and staffing issues that you have observed or had to deal with as you deal with as your staff interacts with diverse constituents?

4. What particular initiatives and programs have your agency undertaken to be responsive to the diverse clientele you serve?

5. What are the types of barriers, both organizational and interpersonal, that you have observed? How are those barriers created or maintained within the agency? What steps does the agency take to eradicate such barriers?

\section{Related Literature}

As has been noted (Allison, 1999, 2000a, 2000c; Collins, 1990; Dovidio \& Gaertner, 1998; Young, 1990), many forms of bias and discrimination reside in deep levels of individual and organizational life. As Young (1990, p. 41) states:

In this extended structural sense, oppression refers to the vast and deep injustices some groups suffer as a consequence of often-unconscious assumptions and reactions of well-meaning people in ordinary interactions, media and cultural stereotypes, and structural features of bureaucratic hierarchies and market mechanisms - in short, the normal processes of everyday life.

At the individual level, well-meaning individuals may manifest unconscious aversive attitudes toward individuals perceived as different from them (e.g., people with disabilities, racial/ethnic minorities, gay/lesbian individuals). These attitudes may manifest themselves in forms of fear, social distance, anger, or hostility. At the organizational level, such perspectives may result in strained interpersonal communication between employers, employees, and/or constituents and may foster or reinforce inequitable organizational programs/policies and institutional/structural inequity. Young (1990, p. 41) adds:

Oppression designates the disadvantage and injustice some people suffer not because a tyrannical power coerces them, but because of the everyday practices of well-intentioned liberal society... Oppression in this sense is structural, rather than the result of a few people's choices or policies. Its causes are embedded in unquestioned norms, habits, and symbols, in the assumptions underlying institutional rules and the collective consequences of following those rules. 
One of the greatest challenges of any organization is to identify, through systematic analysis, the types of barriers and biases that may exist in program delivery and organizational policies and practices.

Recent research from a wide range of agencies indicates that many organizational efforts to respond to diverse constituents are primarily symbolic (Allison, 1999; Cox, 1994; James, 1996; Minors, 1996). While some agencies espouse diversity principles, many are unaware of the systemic barriers that exist as part of their historical, social, and organizational legacy. As Tator (1996) notes:

... the human-service delivery system, has to a significant degree, failed to adapt its programs and services, its administrative systems, and its organizational structures to the reality of a multiracial society. The consequences of this neglect are inadequate and inappropriate services to members of racial, ethnic and cultural minorities. (p. 160)

There are several deeply rooted ideological perspectives that may explain this pattern. First, as Tator suggests, most human service professionals fail to recognize the extent to which programs are embedded within an increasingly multiracial society. Instead, diversity, particularly ethnic differences in values, norms, and behaviors, are assumed to be a temporary state and that, in time these differences will disappear resulting in the homogenization of American culture. As this perspective holds, if ethnic groups (particularly of color) learn and eventually blend into mainstream society, there is no need to diversify program offerings. There is substantial evidence that this process of complete assimilation and homogenization of culture does not occur and the process of cultural development and change is much more complex than traditionally believed (Floyd, 1998; Gramann \& Allison, 1999).

A second explanation that might help explain the lack of human-service responsiveness to diverse constituents may rest in the perspective that diversity only exists in particular neighborhoods, communities, regions, and states. "Those" people require "special" programs but need not be the concern of the large-scale organizational system. Thus, only recreation programs in certain communities and neighborhoods need to concern themselves with the development of programs to meet the needs of their "special" constituents. This perspective overlooks the dramatic demographic changes taking place in most communities.

A third explanation is that most professionals are socialized into a seemingly monocultural society with social institutions that are predominantly designed to meet the needs of the dominant population. These institutions function, often unknowingly, to serve the needs of some taken-for-granted majority population while being less responsive to the needs of minority populations. As muted-group theory suggests, public interaction and systems of language, symbols, and communication within social institutions becomes structured around the often hidden but powerful systems that have been set in place by those in positions of power. Individuals and groups in non-dominant positions become less visible, and in a sense, their voices become muted (Ardener, 1978; Kramareae, 1981; Orbe, 1994, 1998). Young (1990) refers to this as a system of cultural imperialism in that all points of reference become normalized and centered in the dominant experience, while the experience and voice of the others is minimized, stigmatized, or silenced.

\section{Theoretical Framework}

Co-cultural theory, building on the conceptual underpinnings of muted group theory and standpoint theory, suggests that dominant and non-dominant group relations are played 
out in the interactive and communicative experiences of daily life. Orbe (1998) states "cocultural theory works to create a framework that promotes a greater understanding of the intricate processes by which co-cultural groups members (women, people of color, gays, lesbians, bisexuals, etc.) negotiate attempts by others to render their voices muted within dominant society structures" (p. 4). He continues:

Co-cultural theory seeks to provide a framework to gain insight into how those with little or no societal power communicate with those aligned with the power of dominant society structures. Muted-group theory is essential to this examination, as it acknowledges and describes asymmetrical power relations within social hierarchies. An important contribution of co-cultural theory is that it approaches the communication among these groups from the perspective of those without power. (p. 9)

Muted group theory was initially developed by anthropologists Shirley and Edwin Ardener (1975) to explain the experiences of women. It was later adopted to emphasize the experiences of African Americans (Orbe, 1994). Essentially, muted group theory focuses on how language names experiences and thus determines what facets of individual and social meanings and behavior are recognized. It is based on the premise that the structures of daily life reflect the worldview of the dominant mainstream that, in turn, silences or renders invisible the position of non-dominant groups, particularly in the public sphere. For example, Ardener (1978) suggested that the silencing of women manifests itself in many ways including levels of discrimination that are especially evident in public discourse, i.e., women are less comfortable and thus less expressive in public situations than they are in private and women monitor their communications more intensely than men do. Orbe's research on African American men confirmed that minorities have muted voices, which negatively affects various aspects of daily life, including organizational productivity. According to Ardener (1978) and Orbe (1998) muted groups feel that in order to "fit in" they have no choice other than to change the way they act and talk, which indicates power is being exerted and/or lost. Specific gender, racial, or cultural groups cannot be heard for who they are, but rather feel compelled to act in ways that are reflective of who is "listening," the dominant group. Within such a communication system, the non-dominant group cannot effectively communicate because their worldview is not recognized within the dominant discourse.

Muted group theory also attempts to uncover commonalities among subordinate group members as they function in dominant society, while substantiating the vast diversity of experiences among groups. Similarities among the oppressive practices of sexism, racism, heterosexism, ableism, and classism - at personal, social, organizational, and institutional levels - are recognized while concurrently acknowledging the different ways in which these conventions are manifested in the daily lives of subordinate groups (Orbe, 1998).

Standpoint theory emerges from the works of feminist sociologists such as Harding (1987, 1991), Harstock (1983), and Smith (1987). It is premised on the phenomenological underpinning that there are a myriad of alternative understandings of the world, and those historically situated on the margins can provide insights into dominant and non-dominant relations that are often invisible to those in dominant positions. As Smith notes, standpoint theory is capable of "exploring and mapping actual organization and relations that are invisible but active in everyday/every night sites where people take up resistance and struggle, capable of producing a knowledge that extends and expands their and our graph of how things are put together and hence their and our ability to organize and act effectively" (p. 96). Essential to this theoretical approach is the recognition that those who have historically been situated in marginalized positions provide key standpoints and situated perspectives that 
greatly enhance our understandings of the social world. As Orbe (1998, p. 10) states, "The inclusion of co-cultural group experiences is crucial since those with and without societal power have conflicting worldviews; the vast majority of existing scholarship presents only the dominant perspective."

Similar to muted group theory, standpoint theory recognizes the great diversity of experience that links the human experiences of those in non-dominant positions. While one can explore the commonalities of experience, this approach does not presume that individuals in marginalized positions all construe their world in the same way. As Orbe (1998, p. 28) states, "The value of standpoint epistemology is in the ways that it promotes a recognition of what units and differentiates co-cultural groups without necessarily essentializing them."

Co-cultural theory, then, provides a vantage point from which recreation professionals, particularly those from historically disenfranchised groups, can provide important insights into the patterns of communication and interaction that may inadvertently inhibit program attractiveness and access to other historically marginalized groups in our society. In essence, the purpose of this study is to discern ways in which recreation agencies, through policies and practices, might disadvantage marginalized populations. This approach may prove beneficial in providing a level of understanding in the more global concept of leisure service delivery to underrepresented populations.

\section{Methods and Methodological Justification}

The respondents for this exploratory investigation included 18 recreation professionals, including 10 people of color (African Americans, Hispanic, Native American women and men) and 8 Euro-American women who are employed in park and recreation programs in 4 different Southwestern cities. As Orbe (1998) suggests, it is essential that research include the insights and life experiences of individuals from historically marginalized populations. Such individuals have the opportunity to gauge experience from multiple perspectives or what Collins (1990) terms the outsider within stance to the investigation. Their agency experience provided an "insider" view of diversity-related efforts, while their gender and ethnicity perhaps sensitized them to the nature of issues faced by individuals from traditionally marginalized groups (outsider view). As Orbe states:

Standpoint theory contends that the value of these co-cultural perspectives is crucial, since marginalized group members have the ability to see dominant society structures from the position of an "outside-within" perspective (Collins, 1986). In other words, marginalized group members who gain access (albeit sometimes fleeting) into dominant structures have the unique opportunity to perceive the settings from a near and obscure vantage point. (p. 10)

It is important to note that these individuals were not asked to respond as "representatives" of their particular ethnic or gender group. Instead, it is their life history as members of historically disenfranchised groups and their situated positions within the organization that might provide them with particular insights into organizational life.

In addition to their position as members of diverse co-cultural groups, respondents had many years of experience with parks and recreation agencies. The range was from 11 to 30 years of experience in parks and recreation agencies; they had an average of 21 years' experience. The majority of professionals $(83 \%)$ held supervisory and mid-management type positions (e.g., coordinator, center director, program supervisor, and park manager). Many began their parks and recreation careers as part-time employees in recreation agencies in both the United States and Canada. 
Purposive and snowball sampling techniques were utilized to identify participants (Babbie, 1995). Each interview consisted of approximately 20 semi-structured questions (Merton, Fiske, \& Kendall, 1990) covering topics such as professional experience and training, the nature of their organization's philosophy toward diversity, the organizations actual response to issues of diversity, the nature of barriers inhibiting access by users, organizational strategies to deal with changing demographics, initiatives and programs (e.g., outreach) to provide greater access and attractiveness to diverse populations.

Interviews were tape-recorded and lasted $11 / 2$ to 2 hours. A note $\log$ and taped summaries were developed following each interview noting major issues/themes suggested by the respondent. Interviews were subsequently transcribed. The constant comparison method (Lincoln \& Guba, 1985) was utilized as the primary analytic technique. Initial analyses were guided by the general interview questions. During subsequent analyses, a verbal matrix was created that allowed the clustering of common concepts and relevant quotes together (Miles \& Huberman, 1994). The final phase allowed the investigator to refine the organization between the concepts and quotes and develop guiding themes. In order to enhance the trustworthiness of the data, follow-up contact was made with several respondents when response clarification/elaboration was needed (Lincoln \& Guba, 1985; Miles \& Huberman, 1994). Their insights were integrated into the interpretation of data. (In the section that follows, each quote is marked with an identifier and log notation to indicate multiple respondents and maintain participant confidentiality.)

\section{Findings and Discussion}

Interview data resulted in the identification of five major areas that these recreation professionals identified as potential program issues and barriers: (1) the changing face of community, (2) the changing face of management and staff, (3) deferred program responsibility, (4) language barriers and the politics of voice, and (5) management and staff attitudes and stereotypes.

\section{The Changing Face of Community}

One of the initial barriers identified by the recreation professionals was the inability of their agencies to recognize and respond appropriately to the changing nature of the communities served. The demographic profile of agency service areas were often much more heterogeneous than most agencies were willing to admit. Not only were these service areas filled with communities and neighborhoods of diverse constituents, but also many of these areas were undergoing rapid change. Several respondents spoke about the need of recreation programs to better understand the changing face of the their communities:

It used to be that African Americans, Hispanics, Asians more or less lived in pocketed areas so you could offer a different kind of program over there and cover everybody. Now they've got vehicles, they've moved, so they're all over the place now. You will find as many minorities participating in gyms [in formerly all white neighborhoods], something you wouldn't have seen a few years ago. (7/10)

Staff is sometimes the biggest barrier. Staff doesn't realize that the city is becoming more diverse even in [areas typically viewed as middle and upper class]. Even juvenile court, a lot of folks feel that a lot of juvenile crime is in the south, it's all over the city. Staff is perpetuating some of the myths that are going on. [They think] you don't have to hire bilingual staff, that you don't have to hire staff that looks like the community they serve, that anybody can do the job. (11/2) 
As Allison (2000b) and Floyd (2000) note, communities are undergoing rapid change. Neighborhoods and communities that were once predominantly composed of one ethnic group, social class, family structure, or religious affiliation are quickly changing. These emergent communities interface with more established individuals/families/neighborhoods, many of which have their own diverse character and culture. Respondents recognized that even when management realized that efforts must be made to be more responsive to the changing nature of the service community, resource issues were typically used to justify doing things in traditional ways:

I think the cost of change is very real in the public sector. It's easier to do things as you've always done them, you don't have to change forms, you don't have to change communication style, you don't have to print information to get it out to the public to make them aware that you're changing, so if you continue to operate the way you always do, its less costly and unfortunately I think that attitude of how much it costs is the first question asked instead of what are the benefits versus the resources that will be consumed over the long haul." (1/2)

These emergent communities can add a tremendous number of challenges to recreation agencies that must now prepare themselves to be responsive to people from different cultural and societal traditions with different language and communication patterns, and different expectations and histories with government agencies. Not only is there increased competition for resources and services, but there is a need for greater diversity in programming, greater cross-cultural knowledge and sensitivity of staff, and a greater willingness to be responsive in multiple ways to these diverse communities. But as one respondent noted, it could be intimidating for management and staff to understand some of the issues, particularly if he/she had not been raised in diverse environments:

Because [discussing issues of diversity] will call for people to actually step outside the box and think about their behaviors more. Because, again, a lot of this is learned, it's unconscious, we have no idea. Unless you have been in an environment where you are exposed and you have been taught and learn to appreciate differences and be aware of sensitive things that may be sensitive to people that are different, to Latinos, to Indians. They just don't know, they are ignorant about that. (8)

Consistent with co-cultural theory, data suggest that perhaps many recreation agencies may not understand how to be responsive to the needs of these diverse constituents or may only respond at symbolic levels (Allison, 1999). In essence, there was always question about whether or not recreation agencies were simply going through the motions of being responsive but little changed. For example, one respondent noted:

I don't see anyone making an effort to reach out in any one particular area, whether its more Blacks, more Hispanics, more females, I don't see that for users or for employees. The most we've done is put up bilingual signs in some areas, but we don't actively pursue increasing visitation and participation by any special groups. We just say if they like us, they'll come. (4/9)

Several respondents indicated that they believed that individuals from traditionally marginalized groups could tell very quickly whether or not a recreation program was concerned about them. If they felt a recreation center was not responsive, they would simply stop attending. 
In addition to the need for increased responsiveness to the changing face of the community in program delivery and outreach, there was added need to understand how the inter-group dynamics of the community could influence participation patterns for potential users. Several respondents spoke about the potential for increased inter-group conflict and tension among and between these diverse groups to garner program services. Several respondents noted that while many communities were composed of heterogeneous groups that coexisted peacefully, there were other intra-neighborhood community groups who competed for territory and services (e.g., new immigrant groups, differing ethnic populations, long-established neighborhood groups). New immigrant groups would vie for services that sometimes angered the long-established neighborhood groups. As one center director noted, there are programs where only African American youth or Hispanic youth attend despite the heavy representation of each in the community. Another offered:

The Black kids have a history of their parents having come to recreation for years and years there ... from the summer programs and now the after school programs. The Mexican [American] kids will not have that history. They don't know what it's about. You get a few peeking their nose in the door and its all Black in there so they don't come in, the staff is all Black so they don't come in. (17/4)

In such cases, one group (or more) may feel disenfranchised from the recreation centers and will seek out other venues in which to spend their time. Increased efforts will need to be undertaken to insure that all groups feel such programs are attuned to their interests and needs.

In summary, data suggest that there are many challenges facing recreation agencies in understanding the changing faces of their communities. Co-cultural theory helps frame the dialogue from the perspective of the non-dominant groups that use recreation services. Not only is there a challenge for service providers to identify the multiplicity of voices in the community, but there is also the need for management and staff to be provided with the intercultural and interpersonal skills and competencies to respond to these multiple constituents.

\section{The Changing Face of Management and Staff}

A second related area where respondents identified many difficult issues and barriers dealt with the ethnic composition of staff. Because of the changing ethnic composition of their communities, many respondents suggested that the ethnic composition of the staff influenced community perceptions, particularly among the young people.

Whether it be in a community with an increasing Asian population or an Hispanic population, I think the lack of role models, staff that are hired in various parts of the city, that are that ethnic background ... it makes a huge difference. I'm not saying that if you're in a barrio that's $95 \%$ Hispanic, that every single staff person should be Hispanic, but you should have a good representation of Hispanics on the staff. If you don't have that person there, that the client can feel comfortable with initially, then that client might turn away, might not even visit your program. $(3 / 3)$

I think its because they don't see enough people who look like them, or maybe come from where they come from so they can at least relate to someone in the program who's giving it. I know it made a difference for me when I was coming 
up and we had teen centers. Okay, this person can relate to me, kind of looks like me, comes from the area I come from, that kind of thing. (5/4)

Although most respondents agreed that a diverse staff was important to the local community, the selective placement of ethnic minority staff in targeted communities was a difficult and sensitive issue. Such placements provided role models for youth from the community, but it also had the potential to pigeon-hole ethnic minority staff into targeted niches that might not be consistent with their own wishes and career interests (Allison, 1999). Moreover, it deferred responsibility for program diversification from the staff as a whole.

I think a balance is good ... I think people who are qualified or who have experience or want to go into that area need to get the jobs. There's a community that I would say is $99 \%$ Hispanic and last year I put a Black person there. He got raked up and down because he was Black. People were saying stuff and the kids, because they had never interacted with a Black person... Well now he's kind of established there and the kids are used to him and like him, and its good because they see something different. They recognize that we're all people. They need to have role models, but they need to see there is more out there. (17/3)

I think agencies in general want to be responsive, but they struggle on how to be responsive. I think in some way they set up barriers, you know, if you're a Black or Hispanic recreation professional then you're best to work in that community. And I think that creates diversity barriers, I know for me one of the best experiences I ever had was working at an inner city camp when the kids were checking in knives to me at the start of the day and just opening my eyes up to the barriers I set for myself as a professional, and I think that sensitivity needs to be placed on all of us regardless of who the professional is. (9/6)

Although many respondents recognize the benefits of having a diverse staff, many of whom reflect the ethnic composition of the local community, many realize this puts an undo burden on these ethnic staff to act as the minority spokesperson for a particular group. Tator (1996) suggests that such placements may serve as an important short-term organizational strategy, but more inclusive training for all management and staff is important to organizational effectiveness. This is particularly important since most communities are no longer homogeneous but are frequently composed of multiple ethnic communities. Moreover, such placement has the power to defer non-minority staff responsibility from diversity-related issues. As one respondent noted, all recreation professionals should be able to effectively serve in diverse communities and should be required to do so.

Give everybody a chance to work the inner city. Give everybody a chance to work the White part of town. Don't be putting people cause you're Black you gotta work over here, you're White, you can work over there. See we've got White people in this department who have never worked in the inner city. I think that's the biggest joke I've ever seen in my life. They should, if they can't work with inner city people they should not work with recreation, period. They should be able to work with anybody, anybody. (6/9)

Several respondents noted, however, that once community groups felt disenfranchised, it was particularly difficult to change perceptions of non-responsiveness. Such perceptions have the potential to influence long-term program participation. 
[The perception of the community] was that we were kind of unreachable, people who are up here, and we're down here. And if we come to their programs we're probably going to be left out or they won't offer the type of things that we want. And it was the same thing on the other side that's what was so frustrating. Me [as a minority] being in the middle, coming from one area and now being in the work place with the other group, and I could see the fear on both sides. And my struggle was trying to put those fears down so people could really see what was going on. But I think that their perception was that sometimes we didn't care, although we did for the most part ... that we didn't care enough about them to do something for them, that they weren't important enough. (5/3)

These respondents were sensitive to the complex issues that surrounded staffing issues in centers embedded in a multiculturally diverse community. They suggested that there is an essential link between appropriate staffing and program delivery effectiveness. That link is the ability and sensitivity of the staff to appropriately and effectively communicate with the local communities. Respondents made it clear that actual and potential participants could "read" the intentions and perspectives of the program management and staff and depending on the messages sent, subsequent participation would be effected. In essence, programs develop a reputation that may foster program participation or drive particular constituents and communities to other alternatives.

\section{Deferred Program Responsibility: Hey Amigo, What Can You Do?}

In addition to understanding the diverse nature of communities served and hiring a diverse staff that is responsive to a wide range of constituents, respondents indicated that creative and alternative program service delivery strategies were also important to serving diverse constituents. However, respondents noted that often a recreation center's responses to diversity were either misguided and/or ineffective. For example, respondents noted that despite the espoused willingness of many programs to offer culturally relevant programming, few demonstrated an integrated and systematic approach to such planning. Instead, programs for the ethnic minority populations were frequently discussed as "special" programs and left for those staff, typically ethnic minority staff, to design them.

If the individual likes doing the special programming, and really wants to reach out to a particular population, whether its African American or Native American, is pretty much up to that person. If the individual wants to make an effort toward it-I mean, as a whole there isn't this big push to service any type of ethnic group, there just isn't. If we wanted to program a Cinco de Mayo, it would be up to me to do special events for Cinco de Mayo, it would be my choice. And I can tell you, that type of program would not come from my supervisors, it would come from me. $(10 / 2)$

Diversity came up and everyone jumped on it. Sounded great in meetings and when we talked about it, but our actions weren't meeting our philosophy. The department was kind of a reactive group. (5/7)

Such special events were not seen as a central and systemic responsibility of all center employees, but instead were left to individuals, often ethnic minority staff, to develop. Moreover, such efforts were often low in budget priority, and staff had to piecemeal the events together with sparse resources. The label of special programs rang hollow in the minds of several respondents since such programs were perceived as little more than idiosyncratic 
special events designed to serve short-term program goals and placate members of the community.

I think what we do is continue to throw money at the problem or we throw special programs at this population and we say, oh aren't we doing good deeds, oh aren't we special, aren't we really doing our jobs rather than just opening it up, recognizing diversity and truly embracing it. It's lip service in my opinion, unfortunately, we do one or two good little things that have very limited impact and we just tout our greatness on all the good things we have done, and hang our hats on one thing or two things, it is truly incredible to me. (1/7-8)

Often, the language used to communicate the ideals of programming to diverse constituencies was grounded in the dominant culture's ideology. The majority of programs offered were traditional in nature with "special" ethnic festivities created to celebrate diversity. The result was that there was an on-going verbal, and more often non-verbal message communicated of the "special," yet marginal, nature of such programs and that it was really the purview of the "ethnic" staff to take responsibility for such programs. As one respondent noted:

You could often feel it [fear] in the room. It's like someone would say, "I want to do something but I don't know how to deal with those people." So they would look at me, being a minority from a lower socioeconomic background, and say like, "hey amigo, what can you do, or what kind of ideas do you have?" And my thing was, at first I would do that, with open arms, but after awhile I'd say they aren't learning anything by this, and I started to force them to think about it, because it's really not that different if you think about issues and concerns that are there. (5/3)

[As a minority] it was sort of like if you want to take this one, and do this on your own, you can use your resources, your computer, we can print up paper for you, fliers and that kind of stuff, we know its not part of your job responsibility ... it was like "you can deal with them, you know about those kinds of things, so why don't you do it" type of thing. I was encouraged to do it, I was even given an award when I did the first couple of them. (5/8)

Comments such as "those people" and the "hey amigo, what can you do?" reflect a strong distancing by members of the dominant group from the needs and interests of the ethnic minority populations. Not only did such language diminish the worth of the ethnic community and the staff member alike, but it allowed the rest of the staff to pass on their own professional responsibility to all the communities they serve. The ethnic minority staff member (even in cases where the ethnic population did not match the ethnicity of the staff member) often came to serve as the symbolic and real minority representative responsible for the opportunities available to the ethnic populations. Such patterns clearly reflect the systematic ways in which the ethnic community's needs were made invisible and ethnic minority staff was marginalized if they took on the added burden of such "special" programming (James, 1996; Minors, 1996; Pechansky \& Thomas, 1981).

\section{Language Barriers and the Politics of Voice}

Respondents noted that an important barrier to program access and availability dealt with whose voice was communicated (i.e., language barriers) and whose voices were heard (i.e., the politics of voice). These barriers are at the crux of the muted group framework. The 
power relations between the transmitter and receiver of the language significantly impacts relationships and, ultimately, service delivery (Orbe, 1998). Language differences between service providers and constituents were identified as an important barrier to program access and new constituent outreach. Many recreation professionals noted that management and staff were typically only English-speaking, which made it difficult to provide adequate services for non-English speaking communities. The ways that the agency dealt with the language barrier often set the tone for subsequent interactions with the community. As one respondent noted, "It could be language ... it could be perceived if we put fliers out just in English, for example, in what we already know is a predominantly Spanish neighborhood, and we don't put it out in Spanish, that in itself could be a barrier" (16/2). Another respondent noted that the simple observation by community members that little effort was made to reach their community could influence long-term relations. "The language barrier is a big one. A lot of times we set barriers by not marketing or introducing it to new users by ignoring language barriers or cultural barriers. All you have to do is offend a group once and they would be reluctant to come back because now the agency is perceived as insensitive" (9/5).

Many managers spoke about the importance of having bilingual staff to enhance communication and program delivery. Reflective of several comments made, one respondent noted, "We make every effort to hire people who are bilingual. Hispanics are the number one minority... so as we look in areas where we have programming and facilities, people who work at those facilities need to be bilingual" (15/3). Most agreed, though, that there should be a more concerted effort by recreation departments to hire bilingual staff, prepare appropriate materials for the diverse constituents, and insure those materials are distributed.

We've got boxes and boxes of Spanish materials left. Nobody reads them, but we don't distribute them to anybody either, they just sit there. (4/4)

I think the department needs to get more in tune with the need for bilingualism.

We have a tremendous bilingual market out there. Not only Spanish, but there are many other language influences that have come into the area. $(8 / 5)$

Several noted their own frustration with their inability to speak another language. As one community professional noted, however, it is possible to create opportunities with the agency to foster basic language and intercultural skills that would at least provide a basic working foundation for management and staff to reach out to the non-English speaking constituents and community members.

Moreover, several respondents noted that there is a strong politics of voice that determines which community constituents get special program consideration. Many noted the power of outspoken individuals and the proverbial "squeaky wheels" that want special program considerations (e.g., programs, facilities). Assertive and vocal community members, most often from white middle-class neighborhoods, understand how to apply pressure on an agency to achieve their goals (e.g., these individuals knew who to call and what to say).

I think a lot of times employees, politicians, people assume that people of a certain class deserve something where people in a lower class may not. You know it's definitely an issue .... and they've always said the squeaky wheel gets the oil. Well in most cases, the upper class will get the oil before the lower class will because they have a way of knowing how to use the system to get what they want. (7/13)

Another professional noted, "What happened is that they've [Hispanics, AfricanAmericans, the poor] been shunned for so many years by the police, by everybody, that they don't even want to fight anymore" (2/8). Thus, this politics of voice worked effectively for 
some community interest groups while other groups (i.e., the quiet ones) were more easily ignored and marginalized. Several noted that community activism and advocacy may be an important strategy to develop in marginalized communities, but felt it was outside their professional role to take on such issues:

People [some minority groups] are not educated enough to complain, they don't know their rights or anything about it, and as professionals working for government we can't tell them their rights, and we don't have an advocacy group going out and saying, you deserve this. You're a taxpayer, you pay your money, and you need this, fight for it. If they [a particular community] have it over here then you should have it over here, or if they've given you this you need to fight to keep it up. And that's just education that we can't do, so who does it? (2/8)

According to the respondents, the issue of whose voice is communicated and whose voices are heard becomes important when resources are distributed and decisions are made about program development. Traditionally marginalized populations are often silent or silenced and have less experience in knowing how to push for programs they might need or want. Some ethnic populations may not place a cultural value on such activism. Other groups may feel so marginalized from the recreation centers that it would not occur to them to even approach the center. This silencing results in diminished power which ultimately limits the range of opportunities available to ethnic minority communities (Feagin, 1994; Floyd, 1998). As respondents noted, if programs are only marketed and developed with an English-speaking community in mind, then there will continue to be many under-served communities whose primary language of choice is not English. Moreover, if program development relies on the "squeaky wheel" syndrome to meet specialized constituent needs, traditionally marginalized populations will continue to be marginalized.

\section{Management and Staff Attitudes and Stereotypes}

Finally, this marginalization persists because of prejudicial attitudes and stereotypes held by some management and staff toward constituents. As several respondents noted, negative attitudes and stereotypes created persistent difficulty in responding to the needs of ethnically diverse constituents. One respondent noted, "Fifty percent of the White people in our department don't want to work with Black people or minority people" (6/15). Another respondent noted:

I think we still stereotype people from assuming that Blacks act a certain way, Hispanics act a certain way, and Anglos act a certain way. And I think there's a lot going on. When you're in a position of authority, and you have the attitude to assume a certain ethnic group is going to act a certain way, I think you prejudice yourself right off the bat. I don't think you're open to certain things. [These attitudes] are going through some changes, but I wouldn't say its anywhere close to where it should be. (7/7)

Such prejudicial attitudes and stereotypes influenced not only the nature of the interaction of management/staff with community constituents, but they also influenced the nature of program outreach and offerings to particular communities/neighborhoods (Floyd, 2000).

The number one [barrier] is our attitude. Our attitudes towards them, because I know a lot of people in our organization would say, why should we go out of 
our way and do extra stuff for them, when they're not going to do it anyway? It's still those old perceptions and myths about people being lazy and not wanting to do anything for themselves. Why should we help them if they're not going to help themselves? That was the bottom line. That attitude was pretty common even though they wouldn't say it while I was there, but sometimes they would if it sparked a conversation and we were battling back and forth on issues. Someone would just blurt out, "Why do we go through all this trouble, they're not going to show up anyway and then they'll complain about our programs and say we didn't meet their needs and we didn't have what they want." (5/9)

We carry our attitude about our own treatment to the customer; we can't help but do that. If we're angry in the workplace because of a supervisor or blaming it on their ethnicity, or their sexual choice, then we generalize those attitudes to anyone of that population as a whole, and then when we run across that type of population in our public we vent it right on them, we put them right in the same box and then we treat them with less respect because we don't owe them anything. $(1 / 5)$

Several respondents noted that fear of difference was often a factor that influenced decision-making and interactions between staff and constituents. This fear, or discomfort directly influenced the nature of on-going communication and interaction. It inhibits opportunities to reach out to these diverse groups.

When asked if there were attempts to talk to the minority kids in the community about their needs ... Yeah, there was some effort but it was limited. I think it was fear. When you go into those neighborhoods there's a fear to try to get the information to them. Because you can't put that stuff in a booklet and say, come to our meeting and expect them to show up. You have to go into the neighborhoods and pass the information out and make the personal contacts. I don't know if it was fear, physical, personal safety, but it was more a fear of how to communicate. I think because people focus on the differences so much they forget about the similarities. (5/3)

The kids scare some people. There's a difference between a 13 and a 17-yearold. And very few deal effectively with those older kids. Its because they're scared, they don't know how to handle them, they associate them with being gang bangers, and especially if they're Hispanic or African American. They totally stereotype them, and its not being educated and not willing to learn more about it. (10/5)

There can be little doubt that the attitudes and stereotypes that some management and staff hold toward minority participants directly influences the nature of staff and constituent interaction (i.e., initial and subsequent meetings) and program outreach and delivery (Dahl, 1993; West, 1993). As several respondents noted, the tendency for some management and staff to harbor strong negative biases directly affected whom they chose to work with and how programs were developed.

Such attitudes that were often picked up by potential constituents can result in program avoidance or conflict (Allison, 2000b,c; Floyd, 1998; Schneider, 2000; Schneider \& Allison, 2000; West, 1989, 1993). As Pettigrew and Martin (1989) noted, such attitudes and stereotypes exist at deep levels of individual consciousness and are difficult to change. However, as several respondents noted, with strong leadership (e.g., creating an environment that does not tolerate difference and welcomes it) and appropriate staff training opportunities (e.g., mentorship, professional development seminars), important strides can be made in programs to mitigate against some of these issues. 
In summary, the findings of this investigation suggest that recreation programs exist in very complex and ever-changing multicultural, multi-ethnic communities. Changing demographics (e.g., ethnic, social class, family structure) place incredible burdens on recreation programs to deliver effectively to these multiple communities. Despite efforts to deliver effective and responsive programs, the respondents suggest that there are barriers that, even in the most well-intentioned agencies, need to be overcome to improve program responsiveness to ethnic minority constituents.

\section{Discussion, Implications, and Conclusions}

Respondents identified five primary barriers that they perceived inhibited program access and responsiveness to ethnic minority constituents. These barriers included (1) the changing face of community, (2) the changing face of management and staff, (3) deferred program responsibility, (4) language barriers and the politics of voice, and (5) management and staff attitudes and stereotypes. As noted in the findings, each of these barriers posed serious obstacles for the effective delivery of services to ethnic minority constituents. The perception of monolithic communities, which were characterized as the inability to understand the current and emergent nature of diverse communities and neighborhoods, resulted in the creation of less visible, more muted, ethnic/racial constituents (James, 1996; Tator, 1996). The lack of visibility resulted in the continued marginalization of constituents through a void in program development and outreach that met their needs. When special programs were developed they were often idiosyncratic, low in budget priority, and left to ethnic staff to create and administer. Such programs were seen by many of the recreation professionals interviewed as little more than symbolic gestures to targeted community groups (Allison, 1999). The invisibility of ethnic constituents was compounded because of the tendency of agencies to respond to more visible and vocal groups that could muster political pressure to serve their own programmatic interests (i.e., the politics of voice). Such patterns suggested that service delivery was often based on a dominant mainstream model that excluded the less visible, less vocal, and less powerful groups (Allison, 1999; Floyd, 1998; Philipp, 2000; Scott, 2000).

The linguistic issue was another serious barrier to program outreach and delivery. The sheer inability to have two-way communication between client (s) and service provider made meaningful interaction problematic. Not only were day-to-day interactions more difficult, but the development of meaningful marketing and outreach strategies required greater effort and sophistication. Several respondents suggested that it was the responsibility of the agency to develop strategies that would help ameliorate problems, such as hiring bilingual staff, educating management and staff about their own communication strategies, and integrating community volunteers into program development and outreach programs.

The final major barrier was the existence of prejudicial attitudes and stereotypes held by some management and staff. Respondents noted how these attitudes and stereotypes influenced multiple dimensions of service delivery from the initial interactions with potential new customers through on-going program development efforts. Several respondents suggested that lack of understanding, ignorance, and fear drove many of these attitudes. Taft (1977, 124-125) suggests that much of the discomfort in working with diverse cultures emerges from the perceived nature of differences between groups.

The greater the disparity between the familiar and unfamiliar culture, the more difficult it is to bridge the gap. Such factors as language used and known by the members of the new society, its economic structure and level of technology, the size and complexity of formal society and its political structure, its specific ceremonies 
and rituals, and the style of primary social relationships are all highly relevant to the size of that gap.

When agencies are unaware, unable, or unwilling to bridge these gaps, then responsive program delivery is thwarted or compromised.

As most would agree, effective communication is an essential component of an individual's or group's overall success in the U.S. This would include entrée and access to quality leisure services. It was clear that interactive and communicative barriers, as the recreation professionals described and defined them, were not peripheral, but a central component limiting diverse constituents access to leisure services. These types of data, then, suggest that the co-cultural theory may provide another important perspective in efforts to better understand the essential relationship between service providers and diverse ethnic minority constituents and communities. For example, respondents suggested that their agencies often provided programming based on some mainstream model that perhaps ignored the particular interests of ethnic minority participants. As co-cultural theory suggests, such approaches did not give contextual voice to all groups, ultimately excluding people of color. One size does not fit all. Further, language barriers were an obvious indication of diverse constituents being muted or silenced. Recreation professionals simply did not know how to communicate with non-English speaking constituents, let alone how to understand diverse cultural contexts. This communication breakdown negatively effected service delivery to these communities.

As muted group theory suggests (Ardener, 1975; Orbe, 1998), dominant culture communication systems often render non-dominant groups and individuals inarticulate or silenced since they are constrained by the dominant communicative structures that are not representative of their worldview. Dominant groups have a significant advantage over nondominant groups within our society because the communication patterns used have an inherent bias toward the dominant group. Not only are such non-dominant groups disadvantaged politically within society at large, but also for our purposes, this disadvantage expresses itself in the daily lives on ethnic minority populations as they interact in our programs.

The goal of this work was to identify and analyze the types of issues and barriers that recreation professionals, specifically women and people of color, believe exist in the provision of recreation services to diverse ethnic communities. Consistent with standpoint theory, these professionals can offer important perspectives that emanate not only from their experiences as representatives of historically marginalized groups but also their situated positions within these recreation agencies.

One limitation of this work is that it asks recreation professionals to describe what they believe to be the issues and barriers faced by their diverse constituents based on their own experiences as individuals and professionals. The essential next step is to identify, from the perspective of the diverse constituents themselves, what recreation programs do well to meet their needs and what barriers are created that make their community based programs less accessible, desirable, or responsive. Despite this shortcoming, there are several theoretical and methodological considerations that emanate from this work. First, as noted, these data elucidate a few of the initial organizational barriers that may inhibit or block program access among ethnically diverse constituents. These organizational barriers reflected both interpersonal relations between clients and service providers, as well as the institutional policy and program developments that influenced which clients were served. The quality of constituent interaction with staff, the level and type of outreach, the efforts to assess program relevance with traditionally invisible groups, the willingness to program for diverse constituents in a systematic fashion, the ability of the organization to communicate 
openly and freely with diverse constituents, and the attitudes of staff/management toward those constituents provide important insights into the markers of program access and responsiveness.

Second, this organizational perspective provides a different approach to understanding recreation barriers work that has been dominant in the leisure literature. Unlike previous barrier research that focuses primarily on individual barriers/constraints that influence leisure pursuits (c.f. Crawford, Jackson, \& Godbey, 1991; Jackson \& Scott, 1999), this investigation focused on the organizational agency-based barriers that inhibit the perceived or actual program accessibility and availability among ethnically diverse constituents. This type of organizational analysis makes explicit the ways that the agency/community context becomes the intersection or interactional space where power relations, service provider/client relations, intercultural/interpersonal relations, and the like are played out. The agency itself, both literally and figuratively, becomes the context within which these processes evolve. Analytical foci, both research and programmatic, can begin to isolate the dynamics of community/agency interface in order to better understand what processes of organizational inclusion exist and work. Such an approach allows the understanding of "difference" to move beyond particularistic group characteristics toward a more comprehensive understanding of how agencies respond to those differences (e.g., ethnicity, age, social class, gender, sexual identity, ability).

Third, future analyses might focus on the sociological underpinnings of community dynamics and change that influence service development and delivery, particularly among the less visible community groups. Such work could incorporate analytical strategies such as demographic analyses (e.g., community migration and change through census mapping, Floyd, 2000), social networks analysis (Bradshaw \& Long, 1998; Stokowski, 1994; Stokowski \& Lee, 1991), and community ethnography (Lamphere, 1992) to enhance our understanding of the community/agency interface.

Finally, research efforts may provide a greater understanding of the nature of intercultural competencies that are essential to successful and effective program service management and delivery. Lecca, Quervalu, Nunes, and Gonzales (1998) have noted the importance of cultural competency skills in human service management and staff. Cultural competence is defined by Chung (Lecca, et al., 1998, p. 4) as "a set of congruent behaviors, attitudes, and policies that come together in a system, agency, or profession that enables that system, agency, or profession to work effectively in cross-cultural situations." These authors note that too often human service provision is based on a "white middle class perspective" (Lecca et al.) that ignores the salience and consequences of cultural difference in service delivery. Several recreation scholars have noted (Dahl, 1993; Drieser \& Peregoy, 1998; Simcox \& Hodgson, 1993) that park and recreation teaching institutions (e.g., curriculum, textbooks) and community agencies can better prepare students/staff/management in both intercultural competence and communication skills. A more comprehensive approach is essential to prepare students with interpersonal, intercultural, and organizational skills and strategies to work in diverse communities (Drieser \& Peregoy, 1998; Henderson, 1997). If the recreation profession is to overcome and eradicate organizational barriers to inclusion, systematic research, and programmatic analyses must begin to elucidate issues and problems and suggest directions for future success.

\section{References}

Allison, M. (1999). Organizational barriers to diversity in the workplace. Journal of Leisure Research, $31(1), 78-101$.

Allison, M. (2000a). Leisure, diversity, and social justice. Journal of Leisure Research, 32(1), 2-5. 
Allison, M. (2000b). Diversity: Beyond symbolism. In I. Schneider, B. Borrie, \& K. James (Eds.), Proceedings: Social aspects and recreation research: Diverse challenges of our times (pp. 1-6). Tempe, AZ.

Allison, M. (2000c). Diversity in organizational perspective. In M. Allison \& I. Schneider (Eds.), Diversity and the recreation profession (pp. 3-15). State College, PA: Venture Publishing.

Ardener, E. (1975). Belief and the problem of women and the 'problem' revisited. In S. Ardener (Ed.), Perceiving women (pp.1-27). London: Malaby.

Ardener, S. (1978). Introduction. In S. Ardener (Ed.), Defining females; The nature of women in society (pp. 9-48). New York, John Wiley and Sons.

Babbie, E. (1995). The practice of social research (7th ed.). New York: Wadsworth Publishing Co.

Bialeschki, D. \& Henderson, K. (2000). Gender issues and recreation management. In M. Allison \& I. Schneider (Eds.), Diversity and the recreation profession (pp. 73-97). State College, PA: Venture Publishing.

Bradshaw, T. \& Long, J. (1998). A critical examination of the advantages of investigating community and leisure from a social network perspective. Leisure Studies, 17(4), 233-248.

Collins, P. (1990). Black feminist thought: Knowledge, consciousness, and the politics of empowerment. London: Routledge.

Cox, T. (1994). Cultural diversity in organizations: Theory, research, and practice. San Francisco: Berrett-Koehler.

Crawford, D., Jackson, E., \& Godbey, G. (1991). A hierarchical model of leisure constraints. Leisure Sciences, 13, 309-320.

Dahl, R. F. (1993). Principles for effective cross-cultural communication. In A. Ewert, D. Chavez, \& A. Magill (Eds.), Culture, conflict, and communication in the wildland-urban interface (pp. 147-159). Boulder, CO: Westview Press.

Dovidio, J. \& Gaertner, S. (1998). On the nature of contemporary prejudice. In J. Eberhardt \& S. Fiske (Eds.), Confronting racism (pp. 3-31). Thousand Oaks, CA: Sage Publications, Inc.

Dreiser, R. \& Peregoy, J. (1998). Multicultural training in parks and recreation education programs. Parks and Recreation Magazine, (March), 37-47.

Feagin, J. R. (1994). The continuing significance of race: Anti-black discrimination in public places. American Sociological Review, 56, 101-116.

Floyd, M. (1998). Getting beyond marginality and ethnicity: The challenge for race and ethnic studies in leisure research. Journal of Leisure Research, 30(1), 3-22.

Floyd, M. (2000, September). Interregional migration patterns of Hispanics: Research, management, and policy implication. Paper presented at the 2000 Trends Symposium, Michigan State University, Lansing, MI.

Gramann, J. \& Allison, M. (1999). Ethnicity, race, and leisure. In T. Burton \& E. Jackson (Eds.), Leisure studies: Prospects for the Twenty-first century (pp. 283-297). State College, PA: Venture Publishing.

Harding, S. (Ed.). (1987). Feminism and methodology. Bloomington: Indiana University Press.

Harding, S. (1991). Whose science? Whose knowledge? Thinking from women's lives. Ithaca, NY: Cornell University Press.

Harstock, N. (1983). The feminist standpoint: Developing the ground for a specifically feminist historical materialism. In S. Harding \& M.D. Hintikka (Eds.), Discovering reality: Feminist perspectives on epistemology, metaphysics, methodology, and philosophy of science (pp. 283 310). Boston: D. Reidel.

Henderson, K. (1997). Diversity, differences, and leisure services. Parks and Recreation Magazine (November), 24-34.

Jackson, E. \& Scott, D. (1999). Constraints to leisure. In E. Jackson \& T. Burton (Eds.), Leisure Studies: Prospects for the twenty-first century (pp. 299-321).

James, C. (1996). Perspectives on racism and the human services sector. Buffalo: University of Toronto Press.

Kramarae, C. (1981). Women and men speaking: Frameworks for analysis (pp 1-63). Rowley, MA: Newbury House.

Lamphere, L. (1992). Structuring diversity: Ethnographic perspectives on the new immigration. Chicago: University of Chicago Press. 
Lecca, P., Quervalu, I, Nunes, J., \& Gonzales, H. (1998). Cultural competency in health, social, and human services: Directions for the twenty-first century. New York: Garland Publishing, Inc.

Lincoln, Y. \& Guba, E. (1985). Naturalistic inquiry. Beverly Hills, CA: Sage.

Merton, R., Fiske, M., \& Kendall, P. (1990). The focused interviews: A manual of problems and procedures (2nd ed.). New York: Free Press.

Miles, M. \& Huberman, A. (1994). Qualitative data analysis. Thousand Oaks, CA: Sage.

Minors, A. (1996). From uni-versity to poly-versity organizations in transition to anti-racism. In C. James (Ed.), Perspectives on racism and the human services sector (pp. 196-208). Buffalo: University of Toronto Press.

Orbe, M. (1994). "Remember, it's always whites' ball": Descriptions of African American male communication. Communication Quarterly, 42(3), 287-300.

Orbe, M. (1998). Constructing Co-Cultural Theory: An Explication of Culture, Power, and Communication. Thousand Oaks, CA: Sage.

Pechansky, R. \& Thomas, W. (1981). The concept of access: Definition and relation to consumer satisfaction. Medical Care, 19(2), 127-140.

Pettigrew, T. F. \& Martin, J. (1989). Organizational inclusion of minority groups: A social psychological analysis. In J. VanOudenhoven \& T. Willemson (Eds.), Ethnic minorities: Social psychological perspectives (pp. 169-200). Berwyn, PA: Swets North American, Inc.

Philipp, S. (1995). Race and leisure constraints. Leisure Sciences, 17(2), 109-120.

Philipp, S. (2000). Race and the pursuit of happiness. Journal of Leisure Research, 32(1), 121-124.

Samovar, L. \& Porter, R. (1994). Intercultural communication: A reader. Belmont, CA: Wadsworth.

Schneider, I. (2000) Revisiting and revising recreation conflict research. Journal of Leisure Research, 32(1), 129-132.

Schneider, I. \& Allison, M. (2000). The journey toward diversity. In M. Allison \& I. Schneider (Eds.), Diversity and the recreation profession (pp. 281-286). State College, PA: Venture Publishing.

Scott, D. (2000). Tic, toc the game is locked and nobody else can play. Journal of Leisure Research, $32(1), 133-137$.

Simcox, D. \& Hodgson, R. (1993). Strategies in intercultural communication for natural resource agencies. In A. Ewert, D. Chavez, \& A. Magill (Eds.), Culture, conflict, and communication in the wildland-urban interface (pp. 123-134). Boulder, CO: Westview Press.

Smith, D. E. (1987). The everyday world as problematic: A feminist sociology of knowledge. Boston: Northeastern University Press.

Stokowski, P. (1994). Leisure in society: A network structural perspective. London: Mansell.

Stokowski, P. \& Lee, R. (1991). The influence of social network ties on recreation and leisure: An exploratory study. Journal of Leisure Research, 23(2), 95-113.

Taft, R. (1977). Coping with unfamiliar cultures. In N. Warren (Ed.), Studies in cross-cultural psychology Volume 1 (pp. 121-153). NY: Academic Press.

Tator, C. (1996). Anti-racism and the human-service delivery system. In C. James (Ed.), Perspectives on racism and the human services sector: a case for change (pp. 152-170). Toronto, Canada: University of Toronto Press.

West, P. (1984). Urban region parks and black minorities: Subculture, marginality, and interracial relations in park use in the Detroit metropolitan area. Leisure Sciences, 11, 11-28.

West, P. (1993). The tyranny of metaphor: Interracial relations, minority recreation, and the wildlandurban interface. In A. Ewert, D. Chavez, \& A. Magill (Eds.), Culture, conflict, and communication in the wildland-urban interface (pp. 109-115). Boulder, CO: Westview Press.

Young, I. (1990). Justice and the politics of difference. Princeton, NJ: Princeton University Press. 
Copyright of Leisure Sciences is the property of Taylor \& Francis Ltd and its content may not be copied or emailed to multiple sites or posted to a listserv without the copyright holder's express written permission. However, users may print, download, or email articles for individual use. 